\title{
PERSPECTIVAS SOBRE LA VIOLENCIA POLÍTICA EN LA HISTORIA RECIENTE DE AMÉRICA LATINA: ASPECTOS HISTORIOGRÁFICOS, TEÓRICOS, METODOLÓGICOS Y ESTUDIOS DE CASOS
}

\author{
Danny Gonzalo Monsálvez Araneda (Coord.)*
}

Recibido: 7/05/2018//Aceptado: 15/07/2018

\section{Introducción}

Waldo Ansaldi pregunta en el libro América Latina. Tiempos de violencias ¿cuál ha sido la importancia de la violencia política en la construcción del orden en América Latina? Al respecto señala que si bien la violencia ha sido parte constitutiva de la historia del continente desde la época colonial hasta nuestros días, lo procesos que se han desencadenado en el contexto de Guerra Fría o en la historia reciente de América Latina nos dan cuenta que “...entre 1954 y 1989, la violencia política fue un recurso desplegado en situaciones de dictadura, con justificaciones provistas por la Doctrina de la Seguridad Nacional pero también un recurso desplegado para el ejercicio de la dominación en situaciones en las que se mantuvo estable el régimen democrático (paradigmáticamente, en Colombia)", pero no es solamente aquello, también es posible encontrar la presencia de la violencia política “...en aquellos casos en los cuales el fenómeno de la lucha armada estuvo presente, en general en la lógica de la guerra se impuso sobre la lógica de la política" (Ansaldi, 2014:16).

Si bien la violencia política se ha hecho presente en la historia continental de los últimos 40 a 50 años, aquello, en líneas generales, no se condice con la producción bibliográfica sobre este fenómeno, solo en los últimos años se ha producido un incremento de la literatura sobre el tema en cuestión, siendo las experiencias de las organizaciones y movimientos revolucionarios y de los régimen autoritarios del cono sur (violencia estatal) sobre las cuales se ha escrito mayormente. Es más, tampoco ha sido un eje, interés central o prolífico la producción de obras colectivas que busquen dar una mirada de conjunto o bien estudios comparados sobre la violencia política en los diferentes países del continente. En ese sentido, desde el campo de la historia seguimos estando al debe en esta materia. Es por ello que hemos querido hacernos cargos de aquellas omisiones y ausencias, incluso de algunas interpelaciones que nos plantean nuestros estudiantes y colegas a la hora de abordar los derroteros de la violencia política

* Doctor en Historia por la Pontificia Universidad Católica de Valparaíso, Académico en el Departamento de Historia Universidad de Concepción (Chile), monsalvez@gmail.com 
en la América Latina reciente, ya sea desde la historiografía, teoría, metodología o bien con algunos estudios de casos.

El presente dossier busca recoger aquellas interpelaciones y como señala José Pablo Feinmann, nos proponemos entregar una mirada crítica a la violencia, en este caso política, pero no desde la impugnación, sino que desde el conocimiento de ésta; es decir, la crítica a la violencia política pasa por conocer y analizar sus alcances, límites y supuestos (Feinmann, 2012: 10-11).

A partir de lo anterior, hemos extendido la invitación a diferentes colegas, académicos e investigadores, que de una u otra forma han estudiado el fenómeno de la violencia política. Este llamado nos ha permitido construir el presente dossier que hemos titulado "Perspectivas sobre la violencia política en la historia reciente de América Latina: Aspectos historiográficos, teóricos, metodológicos y estudios de casos", el cual contempla seis contribuciones.

En el primero de ellos el Licenciado Yerko Aravena y el doctor Danny Monsálvez de Chile, nos dan cuenta de la producción historiográfica de la violencia política en aquel país. Desde una mirada crítica señalan que si bien la violencia ha estado presente en la historia nacional, por ejemplo desde la construcción de Estado (mirada de larga duración), solamente en los últimos años (desde mediados de siglo $\mathrm{XX}$ ) se puede apreciar un mayor interés de parte de historiadores chilenos por analizar este tema; algunos dando cuenta de la violencia política de los grupos o movimientos insurgentes contra la dictadura chilena, hasta aquellas indagaciones que estudian la violencia política institucional del régimen encabezado por Augusto Pinochet.

Un segundo trabajo corresponde al doctor Eduardo González Calleja de España, quien ha sido uno de los investigadores que más se ha dedicado al estudio de la violencia política, ya sea en la realidad española o europea. El trabajo que nos presenta se propone como objetivo establecer un esbozo general de las tipologías de violencia política, tomando en consideración aquellas variables internas, externas, estructuras y estratégicas que se hacen presentes en su estudio.

Una tercera contribución y ya desde una perspectiva de estudios de casos, nos las proporciona la doctora Gabriela Águila, quien se adentra en lo que fue la "lucha antisubversiva" en Argentina, específicamente lo que fue el accionar represivo de los años setenta en la ciudad de Rosario. Águila aborda, por medio de un balance crítico historiográfico y de algunas claves analíticas, el accionar de la policía, fuerza militar poco estudiada, y cómo esta operó durante el periodo de mayor intensidad represiva de la Argentina.

Un cuarto trabajo nos lo proporciona el Licenciado Javier González, quien se hace cargo de un problema muy poco abordado por la historiografía chilena. Se trata del proceso de relegación, conocido también como "exilio interno", que se impulsó durante la dictadura de Pinochet. Si bien el régimen militar chileno ha sido estudiado con bastante profundidad en su aspecto represivo, de la violación a los derechos humanos, han ido quedando algunos temas rezagados o en un segundo plano. Uno de ellos es la relegación como mecanismo de control y disciplinamiento social y que se enmarca en 
la violencia política institucional del régimen de Pinochet. Desde ese punto de vista, la contribución de González constituye toda una novedad y contribución, la cual nos permite ampliar el análisis sobre lo acontecido durante 17 años de dictadura en Chile.

Siguiendo con los estudios de casos, tenemos la contribución del doctor Javier Puente, quien nos ofrece una mirada de conjunto sobre el conflicto armado en el Perú durante la década de los ochenta (1981-1986), concretamente se trata del enfrentamiento que se produjo entre el Estado peruano, sus fuerzas militares y Sendero Luminoso, lo cual se tradujo en una "territorialización" del conflicto, militarización de la sociedad y el terror de Estado.

Finalmente y desde una perspectiva actual, el doctor Guillermo Lizama aborda dentro del campo de la violencia política, el problema de la violencia electoral en el México del año 2006 al 2017. Por medio de la revisión de prensa e información de la fiscalía busca comprobar como la violencia electoral en aquel país se propone, y con resultados bastante favorables, un cuestionamiento a la democracia y a los procesos electorales. De esta forma, la violencia se ha instalado peligrosamente en el México reciente como una "herramienta de control político, social y electoral".

En consecuencia, a través del presente dossier nos proponemos no solo contribuir a enriquecer los trabajos e investigaciones que se vienen desarrollando en el terreno de la violencia política, sino también aportar nuevos derroteros que permitan seguir abriendo caminos o bien incentivar la producción en éste controversial tema, pero por sobre todas las cosas, nos motiva aportar, por medio de un trabajo colectivo, algunos elementos y perspectivas historiográficas, teóricas, metodológicas y de estudios de casos, que permitan animar el debate y la discusión académica a nivel de los estudios históricos desde México hasta Chile.

\section{Referencias bibliográficas}

Ansaldi, W. (2014). América Latina: tiempos de violencias. Buenos Aires, Ariel.

Feinmann, J.P. (2012). La sangre derramada. Ensayo sobre la violencia política. Buenos Aires, Booket. 
